\title{
¿POR QUÉ ES IMPORTANTE LA HISTORIA? \\ LA ECONOMÍA POLÍTICA DEL DESARROLLO EN DEBATE
}

\author{
Pablo Andrade*
}

Fecha de recepción: 17 de septiembre de 2012. Fecha de aceptación: 6 de marzo de 2013.

\section{INTRODUCCIÓN}

El artículo de Fernando López Castellano, "Economía política del desarrollo, análisis poscolonial y 'malos samaritanos" (López Castellano, 2012: 27-50) abre un debate necesario para los latinoamericanos que trabajamos sobre la teoría del desarrollo. El ensayo nos invita a reflexionar sobre el lugar de las reconstrucciones históricas en los esfuerzos por repensar el desarrollo. En efecto, desde que la teoría del desarrollo diera un "giro institucional" a mediados de los noventa (Evans, 2007: 187-189), este campo reincorporó entre sus conceptos y métodos centrales el estudio de la historia y de la cultura; esta transformación ha revitalizado el crecimiento del enfoque de la economía política, una perspectiva despreciada por la corriente principal de la economía como ciencia a partir de Marshall. Es precisamente este último proceso y sus frutos el que López Castellano invita a criticar, usando para el ejercicio los argumentos esgrimidos desde los estudios poscoloniales y los económicos histórico-comparativos de las experiencias de industrialización en los siglos XIX y XX.

López Castellano afirma que la actual economía política es la "nueva ortodoxia en materia de desarrollo económico" (López Castellano, 2012: 29), pero que al igual que las viejas ortodoxias falla tanto en su aspecto explicativo como en las recomendaciones de política, y que este defecto tiene dos raíces: primera, su incapacidad para dar cuenta del proceso de colonización de los países (actualmente) en desarrollo y, segunda, su "excesivo énfasis en la relación ente instituciones y desarrollo". Nuestro contrapunto establecerá que el argumento de López Castellano resulta teóricamente débil, presenta una línea distorsionada de los desarrollos recientes en teoría del desarrollo, y nos reconduce hacia una perspectiva a-histórica del desarrollo posible en América Latina.

\footnotetext{
* Coordinador del Programa de Estudios Latinoamericanos de la Universidad Andina Simón Bolívar, Sede Ecuador. Correo electrónico: pablo.andrade@uasb.edu.ec
} 


\section{LA NUEVA ECONOMÍA POLÍTICA COMO RESCATE DE LA HISTORIA: CONSECUENCIAS METODOLÓGICAS}

Tal vez el texto que mejor sintetiza los supuestos teóricos de la nueva economía política sea Why Nations Fail (Acemoglu y Robinson, 2012); en él los autores afirman que la explicación más general a las diferencias en niveles de pobreza y estándares de vida entre los países capitalistas desarrollados y los que están en vías de desarrollo (capitalista), es que estos últimos son pobres porque "han sido gobernados por una pequeña élite que ha organizado la sociedad en su propio beneficio a expensas de la vasta mayoría del pueblo. El poder político ha sido estrechamente concentrado, y se ha usado para crear gran riqueza para quienes lo poseen" (Acemoglu y Robinson, 2012: 3). ${ }^{1}$ Esta explicación indica que los factores a estudiarse desde la economía política del desarrollo son bien diferentes a los propuestos por la economía científica mainstream, esto es, no el crecimiento económico y la distribución de sus beneficios per se, sino cómo se obtienen. La reconstrucción y el análisis histórico están en el centro del tema; en efecto, el acento del estudio recae en el examen de dos conjuntos de grandes procesos históricos: en primer lugar, el surgimiento de la élite en el poder -o para ser más precisos, de las que se han turnado en el control del aparato estatal- dentro de un cierto marco institucional; y, en segundo, los modos e instrumentos que han usado ésas para mantener o crear concentración de poder y riqueza. Un segundo supuesto general que subyace a este tipo de examen es la manera en que los ciudadanos adquieren poder político; esto es, el análisis de la economía política se enfoca en las transformaciones políticas que una sociedad pobre requiere para hacerse rica (Acemogluy Robinson, 2012: 4).

Si bien es cierta la afirmación de López de que algunos de los estudios contemporáneos en economía política del desarrollo se basan en la perspectiva y métodos de la teoría de la acción racional (rational choice theory), también lo es que esa opción ha sido aplicada al tratamiento de teorías especiales, es decir, de aspectos específicos, tales como: la explicación de la fragilidad de los estados africanos contemporáneos (Besley y Persson, 2011: 8-10), las trayectorias hacia formas de gobierno democráticas o autoritarias (Acemoglu y Robinson, 2006:24), o las iniciativas de reforma del aparato administrativo estatal en América Latina (Geddes, 1999: 30). Vale la pena destacar que aun cuando esos esfuerzos se comparten con otros, de inspiración más estructuralista que

Salvo indicación en contrario, todas las traducciones son responsabilidad del autor. 
de teoría de la acción racional (Evans, 2007; Chang, 2009), su acento en el estudio de cómo se generan y sostienen patrones institucionales, también es cierto que ese realce no es "excesivo", ni necesariamente "anacrónico" o recurre reiteradamente "al contra fáctico de los mundos posibles" (López Contreras, 2012:43).

Cuando los economistas políticos del desarrollo emplean modelos matemáticos para simular las opciones y decisiones que confrontan los gobernantes, mantienen como una constante histórica ("endogenizan" en su lenguaje) el hecho de que los gobernantes normalmente encuentran que su propio poder -y las posibilidades de usarlo para enriquecer a quienes los apoyandepende del mantener inmóviles un conjunto heredado de configuraciones "sistemáticas de expectativas compartidas, presunciones dadas por hecho, normas aceptadas y rutinas de interacción que tienen fuertes efectos en la configuración de las motivaciones y el comportamiento de conjuntos de actores sociales interconectados" (Chang y Evans, 2001, citado en Evans, 2007: 189); esto es, los gobernantes sostienen en su propio beneficio el marco institucional heredado. ${ }^{2} \mathrm{El}$ procedimiento metodológico de los economistas políticos ciertamente tiende a presentarse como una simplificación, sin embargo, los argumentos desarrollados, incluso por quienes llevan al extremo la modelización matemática (véase por ejemplo Besley y Persson, 2011: 6 y Besley, 2006: 11), fuerzan a los practicantes de la nueva economía política del desarrollo a tomarse en serio la historia de las decisiones políticas de esos gobernantes y el hecho de que éstos no controlan los efectos de esas decisiones. Ante la creación de efectos no intencionales, quienes buscan explicaciones no funcionalistas de los procesos de desarrollo simplemente no pueden ignorar los patrones complejos que emergen de la combinación de factores simples, tales como la asimetría de información entre gobernantes y ciudadanos, el establecimiento de círculos virtuosos y de refuerzo de dependencia de trayectoria, oportunidad y secuencia, y el despliegue de procesos de largo plazo, así como el mero azar (Pierson, 2004:15-16).

Dos consecuencias metodológicas se derivan de lo dicho. En primer lugar, los análisis de economía política quedan abiertos a la prueba de la historia, esto es, incluso los modelos más altamente formalizados pueden ser rebatidos por el estudio cuidadoso de la evidencia histórica. En segundo, la consideración de la temporalidad y su despliegue obliga al economista político a efec-

2 Una comprobación que podría ser trivial, de no mediar el hecho de que cuando los gobernantes impulsan cambios institucionales -e incluso transformaciones radicales- la lógica del beneficio propio continúa operando. 
tuar indagaciones históricas que por fuerza deben prestar atención tanto a la secuencia específica de continuidad y cambio de un caso, como a lo que puede aprenderse de éste en contraste con otros; las lecciones que pueden aprenderse de la reconstrucción histórica son puestas a prueba mediante un ejercicio comparativo. Estas dos condiciones metodológicas son un saludable llamado de atención al estudioso que va contra el anacronismo, y no como afirma López Castellano, un incentivo para la proyección en los estados premodernos de las condiciones de los siglos XIX y xx (López Castellano, 2012:43).

\section{ARGUMENTOS HISTÓRICO-COMPARATIVOS EN EL ANÁLISIS DEL DESARROLLO ECONÓMICO}

Una evaluación neutra de la tradición renovada de la economía política mostraría que esos supuestos teóricos y procedimientos empíricos se encontraban ya en el origen de la disciplina, en autores como Smith, Ricardo, Mills y Marx, tal vez el último de los clásicos de la economía política. Por ejemplo, tanto el libro tercero como el cuarto de la Investigación sobre la naturaleza y causas de la riqueza de las naciones (Smith, 2000 [1776]) están dedicados a mostrar, por medio de la comparación histórica, cómo los gobernantes europeos favorecieron el desarrollo de "actividades económicas propias de las ciudades" en beneficio de "los intereses privados o [...] de determinados estamentos sociales, sin tener en cuenta o prever sus consecuencias en el bienestar general de la sociedad" (Smith, 2000:5). La cita permite además mirar otro componente de la herencia y la práctica contemporáneas de la economía política, la preocupación -el sesgo ético diríamos- por las consecuencias de las decisiones económicas para el conjunto de la sociedad.

Si la indagación histórica comparativa está en el núcleo conceptual y metodológico de la economía política ¿en qué se funda la crítica de López Castellano? En la presentación de esa historia a manera de "narrativas", concretamente de una narración supuestamente lineal de la evolución que idealmente habría ocurrido en Europa occidental entre 1500 y 1800 y que llevaría al descubrimiento de las "buenas instituciones" propias del Estado moderno -y del capitalismo. Hay un problema ciertamente en esto, pero no tanto en los argumentos de los economistas políticos, sino en el de López Castellano, porque quienes cita como los creadores de esa narrativa (Levi, Tilly, véase López Castellano, 2012:30-32) no son economistas políticos, sino sociólogos a la caza de argumentos históricos para probar sus afirmaciones sobre el desarrollo del Estado moderno en Europa. 
El argumento de los economistas políticos del desarrollo es diferente. Empieza por otorgarle un lugar prominente a la contingencia y a los procesos de lento desenvolvimiento; concretamente, el argumento afirma que comenzando con los devastadores efectos de la peste negra en Europa Occidental, hubo un lugar -el menos propicio aparentemente- donde se desarrollaron las instituciones políticas y económicas que iniciarían ese largo proceso de desestabilización, destrucción y equilibrio puntuado que conocemos como desarrollo económico (o para dejar de usar eufemismos que tienden a confundir el debate, simplemente "capitalismo"); fue Inglaterra. En otros lugares del mundo europeo la fortaleza de las aristocracias terratenientes vis-à-vis los campesinos impidió el desarrollo de instituciones políticas que fuesen simultáneamente centralizadas y pluralistas (inclusivas), hasta iniciado el siglo Xx en los casos extremos de Alemania y Austria, y todavía hoy en día en Rusia y Bielorusia (Acemoglu y Robinson, 2012:92-96). De hecho en la mayor parte de lo que hoy llamamos "Europa", como ocurre actualmente en buena parte del mundo en desarrollo y muy particularmente en América Latina, una centralización política incompleta o, más frecuentemente, la debilidad o deliberada destrucción de las instituciones que permiten el pluralismo político favorecieron el mantenimiento incluso de manera reforzada de instituciones políticas extractivas, lo cual no impidió el crecimiento económico de esos mismos países -como de hecho ocurre también ahora con los países africanos y latinoamericanos.

$\mathrm{El}$ argumento no afirma, por lo tanto, que un conjunto de instituciones entendido de manera simplista -y en su forma extrema, caricaturesca, las instituciones británicas, o sus retońos en otras partes del mundo que alguna vez fueron parte del imperio británico- es el correcto y universalmente recomendable. El argumento simplemente indica que no es posible que los beneficios del crecimiento económico alcancen a quienes viven más allá de la élite gobernante y los grupos sociales que la sustentan, sin que haya primero una cierta centralización del poder, y la posibilidad de que ésta sea regularmente disputada por los ciudadanos (pluralismo). Queda claro que la evidencia histórica -y contemporánea- efectivamente respalda esas afirmaciones, pero no a la manera de una narrativa lineal, sino considerando las contingencias propias de cada situación: no es procedente igualar el desarrollo que se da en Alemania desde la segunda posguerra del siglo XX con, digamos, el de Namibia.

Sin entrar en mayor detalle examinemos brevemente el resultado de un ejercicio de análisis histórico al estilo de la economía política del desarrollo. A pesar de que en los dos casos, en periodos históricos comparables -digamos entre 1840 y hoy día- se produjo un crecimiento económico importante, las diferencias en pobreza y nivel de vida de sus poblaciones actuales pueden 
explicarse precisamente por una coyuntura clave, la instalación o no de un conjunto de instituciones económicas y políticas incluyentes. En el primer caso, Alemania, esa instalación sólo ocurrió cuando se produjo la total destrucción del orden preexistente en un largo proceso histórico que se inició con la destrucción del imperio alemán en 1918, continuó con el intento fallido de establecer instituciones políticas pluralistas en la República de Weimar y el golpe de Estado auspiciado por los junkers que llevó al partido nazi al poder, y culminó con la derrota alemana en la segunda guerra mundial, hecho que trajo la destrucción definitiva de la clase antidemocrática por excelencia, los junkers, y el inicio de nuevas instituciones pluralistas a partir de 1948. En Namibia, en cambio, la prolongada dominación colonial, primero de Alemania (hasta 1918) y luego de la primera guerra mundial de Sudáfrica, no hizo sino instalar y consolidar instituciones que concentraban el poder en una pequeña élite, la misma que logró cambiar la economía básicamente agrícola de los habitantes del territorio de Namibia en una economía mineral basada en la explotación depredadora de la población y los recursos naturales. Esta situación no cambió mayormente luego de la independencia (en 1989), de hecho se ha mantenido en gran medida hasta la actualidad. Después de la independencia la élite organizada en el sWAPO, por sus siglas en inglés, desarrolló -sobre las bases coloniales- instituciones políticas centralizadas, pero no pluralistas que permitiesen corregir las distorsiones de la economía del país, así un crecimiento económico basado en la depredación continúa hasta hoy.

Un economista político diría que el hecho de que el promedio de duración de la vida en Alemania sea uno de los más altos del mundo, mientras que el de los ciudadanos de Namibia es de apenas 43 ańos (con 21\% de su población afectada por el SIDA) puede y debe explicarse apelando a lo que nos indican las historias de los desarrollos en los dos países. Más específicamente, el análisis tendría que considerar un hecho fundamental: que ambos casos producían resultados más o menos similares en términos de pobreza, conflicto social y muerte, mientras los grupos selectos lograron resistir la instalación de instituciones inclusivas, y que esos resultados difirieron significativamente cuando en uno de esos casos (Alemania) las élites fueron derrotadas y el marco institucional cambió, mientras que en el otro (Namibia) la derrota no significó sino su reemplazo por otro grupo que mantuvo el mismo marco institucional excluyente. El progreso de la economía política del desarrollo ha consistido en generalizar ese descubrimiento, haciendo uso de un conjunto de ejercicios comparativos similares al que se ha descrito brevemente - pero con el debido grado de profundización en los "detalles" de la composición de esas élites, el surgimiento de los respectivos marcos institucionales, su secuencia, 
etc. La conclusión puede parecer obvia, pero no por ello es menos importante: la historia cuenta, y hay que contarla no simplemente para establecer "narraciones" sino para identificar relaciones y secuencias causales que permitan corregir o eliminar las generalizaciones simplistas de una ciencia económica a-histórica.

\section{CONTINUIDAD INSTITUCIONAL: EL PORQUÉ LOS ARGUMENTOS POSCOLONIALES NO SON UNA BUENA CRÍTICA DE LA HISTORIA}

Una vez que López Castellano construyó un perro de paja con los argumentos históricos de la economía política, busca una alternativa. El autor sostiene que los estudios poscoloniales constituyen una sana prevención para evitar el "error [de] generalizar el relato sobre las bases institucionales del 'milagro europeo' [...] a países no europeos". Esta prevención salvaría a quienes estudiamos el desarrollo de "caer en el mito de la modernidad, sustentado en la idea de la superioridad europea y su proyección a las sociedades 'tradicionales' [...]" (López Castellanos, 2012:35). Los estudios poscoloniales, según el autor, constituirían tal cura en salud porque proveen una "narrativa histórica" más atenta, cuidadosa y afincada en la cultura de los pueblos del Tercer Mundo que la que cuentan los estudios de la nueva economía política.

La posición parece razonable, pero merece examinarse con cuidado. Como se muestra en la sección anterior, los estudios de economía política no necesariamente adoptan una posición modernizante, o europeo-céntrica, esto es, la crítica poscolonial constituye una muy bienvenida prevención para el estudio de los trabajos contemporáneos de economía política, en tanto que ayudaría al lector ingenuo a detectar esos sesgos ideológicos que favorecen lo que Evans ha llamado el "monocultivo institucional"; resulta, sin embargo, que esos sesgos no son consustanciales a la nueva economía política del desarrollo sino a las "recomendaciones" de política económica formuladas por las instituciones financieras internacionales, las agencias de cooperación para el desarrollo, e incluso algunas ong del Primer Mundo. Se trata, por tanto, de una crítica política, que no afecta a la economía política en sus supuestos teóricos ni, tampoco, en sus procedimientos metodológicos.

Hay una segunda dificultad en la posición de López Castellano, contrariamente a lo que afirma, la nueva economía política del desarrollo no desprecia "el legado [para los gobernantes posindependencia] en el terreno de la formación del Estado y la integración económico-nacional” (idem). Todo lo contrario, los estudios contemporáneos de economía política insisten en que esa 
herencia histórica debe tomarse en cuenta, pero no en los términos propuestos por la teoría del sistema mundo y sus derivaciones poscoloniales, ni tampoco postulando un contra-factual tan fácil de argumentar pero tan difícil de sostener como el supuesto aborto "de la evolución endógena de las colonias" (López Castellano, 2012:36). De hecho, al menos en este plano específico, los argumentos poscoloniales citados por López Castellano no rebaten, sino que apoyan -aunque sin añadir mayor cosa en cuanto a conocimiento- los descubrimientos de la nueva economía política.

En efecto, los economistas políticos no consideran al "hecho colonial" como un mero paréntesis en la historia de los pueblos colonizados, como sostiene López Castellano, sino que afirman que las condiciones actuales de los países del Tercer Mundo, que sufrieron la colonización europea, encuentran su origen de largo plazo en ese episodio histórico. La mayor diferencia entre los intentos poscoloniales por ofrecer una versión distinta de la historia y los descubrimientos de la economía política reside en que los primeros, al dar un salto desde el estudio de la historia a la crítica ontológica del despliegue de la razón moderna europea -esto es, de la historia a la filosofía de raíces heidegguerianas- terminan por postular una nueva ontología que coloca en el centro de la perspectiva las condiciones geográficas o culturales como bases de una diferencia absoluta en los modos de construcción de subjetividad de los pueblos colonizados y los europeos. Obviamente, aceptada esa operación es fácil concluir que "la lógica colonial, que fue de la mano de la expansión y el desarrollo capitalista industrial europeo, sigue vigente". En esto hay un problema epistemológico, el salto de la explicación o la descripción histórica a la ontología deja sin resolver la pregunta por la continuidad de la "lógica colonial"; en efecto, la respuesta poscolonial de que la continuidad puede atribuirse a la naturaleza misma del poder o de la "razón europea" es insatisfactoria, incluso desde las propias bases teóricas del poscolonialismo, porque "el poder" no puede ser simplemente un postulado abstracto, ni tampoco porque puedan ignorarse con facilidad las crisis, fracturas y heterogeneidad de los diferentes trayectos de eso que llaman "la razón europea".

Ciertamente, ningún estudioso contemporáneo del desarrollo en América Latina, África o Asia puede dudar de que la mayor parte de los problemas contemporáneos que experimentan esos pueblos se originan en las conductas de unas élites que han actuado o siguen comportándose como si los ciudadanos de los países que gobiernan fueran meros sujetos pasivos de las operaciones -supuestamente racionales- de los estados; esto es como colonizadores. El problema surge cuando encontramos que esas élites actúan de esa manera incluso cuando han abrazado -o han creado, como fue el caso de Frantz 
Fannon-algunos de los más radicales ideales anti (pos y de) coloniales. Nada en los estudios poscoloniales y su elaborada ontología permite explicar -o incluso simplemente interpretar- satisfactoriamente ese comportamiento. Curiosamente, los estudios poscoloniales en lugar de enfrentar el problema simplemente dan un salto hacia el costado, y optan por una receta -que por cierto comparten con la teoría de la modernización- para curar el mal: cambiar la mentalidad colonializada, mediante un proceso de "de"-colonialización del poder (así, en abstracto).

La persistencia de "la estructura de dominio" no es un dato que deba aceptarse, sino uno que debe explicarse. Las contribuciones de la economía política en este aspecto son bastante más útiles que las especulaciones de la ontología poscolonial.

Las élites poscoloniales se instalaron en la cumbre de un conjunto de instituciones extractivas pero sin modificarlas, simplemente dirigieron las rentas que fluían hacia las metrópolis para beneficiarse a sí mismas. En los casos africanos las nuevas élites se encontraron comandando -y siendo gobernadas por- instituciones creadas por los poderes europeos en el siglo xIx; en América Latina la herencia institucional, mezclaba los antecedentes creados por los grandes imperios indígenas precoloniales y las instituciones heredadas de la tradición medieval ibérica (Acemoglu, Johnson y Robinson, 2001:13721376). Este desarrollo no tuvo que ver con la mentalidad (eurocéntrica) de esas élites -aun cuando las imágenes de Europa y el mundo desarrollado sin lugar a dudas hayan tenido un papel decisivo en los intentos de esos grupos por crear nuevas sociedades (Scott, 1998:34) - sino con las condiciones en las que las nuevas élites podían realmente ejercer y retener el control del Estado. Examinemos brevemente esa situación.

Los poderes coloniales europeos, una vez que ganaron el control de los territorios de los actuales países en desarrollo, crearon a un alto costo -que pagaron los conquistados-instituciones que defendían sus derechos de propiedad; casi por definición, los colonos constituían un grupo reducido del total de la población que habitaba los territorios de la nueva colonia, por lo que las recientes instituciones políticas y económicas no podían sino beneficiar de manera desproporcionada a esa pequeña élite. Estas condiciones se mantuvieron luego de las independencias de las colonias. Las nuevas élites gobernantes eran casi tan pequeñas como la antigua colonial, en muchos casos habían sido los funcionarios del aparato administrativo colonial, y los costos del cambio a instituciones inclusivas para las nuevas élites eran (son) extremadamente altos (riesgo de perder el poder, o las propiedades, por ejemplo). Como se ve, no es necesario postular ningún tipo de subjetividad o mentalidad especial (v.g. "co- 
lonializada"), basta con tener en cuenta que hubo complementariedad entre las instituciones políticas (autoritarias) establecidas por la élite colonial y las instituciones económicas (extractivas, rentistas) que permitían que el grupo en el poder no sólo se beneficiara sino que además invirtiera en el mantenimiento del orden creado (por ejemplo, mediante el pago a ejércitos, o en la creación de casas de exportación, o minas, o haciendas) (Acemoglu, Johnson y Robinson, 2001:1376). Las nuevas élites no podían sino encontrar razonable -aunque no necesariamente racional- el mantener las instituciones vigentes, con unos pocos ańadidos de maquillaje, y expandir el control del Estado a nuevos aspectos de la vida de las poblaciones sujetas.

Aún más, los estudios de economía política han precisado los mecanismos que dieron origen a dos formas distintas de colonización que, a su vez, explican las distintas instituciones político/económicas que continuaron en el periodo posindependentista. Esta identificación permite, a su vez, explicar los grados de diferencia entre los actuales países en desarrollo. El patrón descubierto es bastante simple: en lugares en los que los europeos podían ser diezmados por enfermedades tropicales como la malaria o la fiebre amarilla, la estrategia de colonización fue en parte influida por este factor: los europeos establecieron formas autoritarias extremas de Estado, e impusieron instituciones económicas radicalmente extractivas, como en el "Estado libre del Congo". Una vez establecidas esas instituciones, las revoluciones independentistas no lograron cambiar las instituciones políticas o económicas, como en la República del Congo bajo Mobutu. Un patrón muy distinto se produjo en los países con climas templados y condiciones ambientales relativamente más benignas para las poblaciones europeas, como en Australia, Estados Unidos o Canadá (Acemoglu, et al., 2001:1395). Una tercera variante que combina factores climáticos con abundancia (relativa) de mano de obra son las instituciones creadas por los conquistadores españoles en los virreinatos de Nueva España y el de Perú.

Sólo para enfatizar lo poco que puede ganar el estudioso del desarrollo al incorporar en su panorama la crítica poscolonial, compárese la reconstrucción de los párrafos precedentes con la que ofrece López Castellano a partir de los argumentos poscoloniales:

[En África] se habla de "Estado transplantado" [... y de "Estado neopatrimonial" [...] una estructura política centrada en el consumo suntuario y absoluto desprecio por la inversión productiva. Más que de Estado en el caso africano hay que hablar de una simple estructura burocrática de explotación, incapaz de proveer ley y orden, contratos e infraestructuras (López Castellano, 2012:37). 


\section{CONTRIBUCIÓN ESTRUCTURALISTA: CRÍTICA AL MONOCULTIVO INSTITUCIONAL Y DESARROLLO DE CAPACIDADES ESTATALES}

Sería injusto afirmar que la crítica de López Castellano está completamente descaminada. En efecto, es claro que la nueva economía política del desarrollo -sobre todo sus ejercicios más econométricos- ha contribuido a la ortodoxia de las recomendaciones sobre "buenas prácticas" y "transplante institucional" que hizo el núcleo de las políticas de las instituciones financieras internacionales en la segunda década de los noventa. Este último es un aspecto resaltado por López Castellano, pero sólo superficialmente.

Los economistas políticos de inspiración estructuralista como Rodrick, Evans y Chang han mostrado que esas recomendaciones de política económica revelan una enorme ceguera de la ortodoxia económica a los procesos históricos reales que permitieron a los países capitalistas avanzados industrializarse rápidamente, y que de hecho las reconstrucciones históricas de esa ortodoxia ciertamente padece de una sospechosa "amnesia" con relación al grado de participación de los estados del Primer Mundo para apoyar el desarrollo de su industria -incluido por supuesto el hecho colonial.

Los estructuralistas no esperan que los economistas del desarrollo imaginen políticas anticapitalistas, poscapitalistas o -peor aún- "decoloniales", sino que llaman su atención al hecho de que los análisis y recomendaciones de las instituciones financieras internacionales descuidan los factores institucionales que aumentan la competitividad internacional de los capitalistas locales de los países en desarrollo vis-à-vis los países capitalistas avanzados. Los estudios estructuralistas muestran que esos factores institucionales dependen de al menos dos grandes componentes: el logro de capacidades fiscales para recolectar impuestos y, por lo tanto, contar con los instrumentos para disciplinar a los capitalistas orientando sus inversiones hacia la industria y no a actividades especulativas; y la conquista de capacidades burocráticas que hagan posible a los estados dirigir sus economías, al proveer estímulos para la inversión industrial, favorecer la innovación tecnológica endógena, lograr coordinación entre los capitalistas y apoyarlos en la conquista de mercados internacionales. En este sentido la crítica estructuralista complementa, no rebate, los descubrimientos de la nueva economía política del desarrollo.

Un tercer factor de desarrollo capitalista exitoso, que Evans ha resaltado muy especialmente, es la creación de instituciones políticas que abran las puertas de la toma de decisiones a los ciudadanos comunes, esto es, la construcción de lo que en el lenguaje de la nueva economía política se llama "instituciones incluyentes". El trayecto de desarrollo presidido por un estado aliado con los 
empresarios puede ser ciertamente muy bueno para el crecimiento económico-mírese la China contemporánea, por ejemplo-pero en la medida que ese crecimiento se concentra en proveer ganancias extraordinarias para los capitalistas locales, fácilmente puede desviar el curso de la industrialización hacia la formación de una economía altamente protegida, con muy poca innovación tecnológica y con empresarios más interesados en mantener y expandir sus rentas que en invertir productivamente, como de hecho ocurrió en India antes de las reformas de Singh (Chibber, 2003:170-192).

En pocas palabras, no se trata solamente de cómo reaccionan los capitalistas de un país en desarrollo al doble proyecto estatal de industrialización y construcción de Estado (v.g. expansión de las capacidades estatales) sino también de si tienen o no los medios, reglas y valores políticos que permiten a los gobernantes y a los ciudadanos contrapesar la influencia política de esos capitalistas. Este punto, sin lugar a dudas parcialmente descuidado en la mayoría de los estudios de la nueva economía política, es fundamental, y tiene implicaciones políticas para los capitalistas como clase, pero no necesariamente para el capitalismo como sistema económico: los capitalistas deben ser políticamente debilitados para garantizar que su resistencia a las medidas disciplinarias -o simplemente de guía- del Estado será mínima; alternativamente podría tenerse una clase capitalista muy fuerte (como en Corea del Sur, India o Brasil, sólo para citar los más destacados ejemplos internacionales contemporáneos) pero su poder debería estar balanceado por la presencia de sectores populares organizados -como el movimiento obrero en la transición a la democracia en Corea del Sur, las bases sociales del Partido del Congreso en India, y el poder de los sindicatos en el pт brasileño.

\section{REFLEXIONES FINALES: UNA VUELTA MÁS A LA HISTORIA}

Los análisis contemporáneos de la economía del desarrollo no pueden prescindir del estudio históricamente arraigado de las instituciones que emergen y hacen las trayectorias de desarrollo de los distintos países. Como se ha mostrado, esta necesidad fuerza a la economía política a dialogar intensamente con historiadores (económicos y no), economistas del desarrollo y cientistas políticos. El debate sobre las instituciones, como se ve a lo largo de este trabajo, es básicamente un puente que ha logrado comunicar esas disciplinas, parece razonable el preservarlo, por lo menos hasta que encontremos un conjunto conceptual de mayor poder explicativo. Hay riesgos en el intento, por supuesto, pero como bien lo anotó Barrington Moore en su trabajo clásico (Moore, 
2002), la atención cuidadosa a desarrollos históricos específicos, alerta al estudiosos sobre procesos sin garantías en cuanto a sus resultados, y la presencia de contextos internacionales cuyas dinámicas de transformación pueden contradecir la formación de instituciones que, en el pasado, favorecieron la corrección de los devastadores efectos sociales, políticos y culturales que el despliegue del capitalismo inevitablemente provoca.

El camino alternativo que sugiere López Castellano, en cambio, es muy poco prometedor. Si la economía del desarrollo abrazara, acríticamente, la ontología poscolonial, bien podría terminar produciendo una teoría barroca y ahistórica. La vigilancia epistemológica sobre la adopción acrítica de modelos ideales de desarrollo por parte del estudioso en economía del desarrollo es una recomendación laudable, pero como he mostrado el camino más adecuado a ese propósito parecería pasar no tanto por la enrarecida atmósfera de la filosofía y los estudios culturales, sino por el barro de la contingencia histórica.

\section{BIBLIOGRAFÍA}

Acemoglu, Daron y James Robinson, Why nations fail: The origins of power, prosperity, and poverty, Nueva York, Random House, 2012.

Acemoglu, Daron; Simon Johnson, y James Robinson, "The colonial origins of comparative development: An empirical investigation", The American Economic Review, vol. 91 (5), 2001, pp. 1369-1401.

Acemoglu, Daron y James Robinson, "De Facto Political Power and Institutional Persistance", The American Economic Review, vol. 96 (2), 2006, pp. 325-330.

Besley, Timothy y Torsten Persson, Pillars of prosperity: The political economics of development clusters, Woodstock, Princeton University Press, 2011.

Besley, Timothy, ¿Principled agents? The political economy of good government, Oxford, Oxford University Press, 2006.

Chang, Ha-Joon, ¿Qué fue del buen samaritano? Naciones ricas, politicas pobres, Buenos Aires, Universidad Nacional de Quilmes, 2009.

Chibber, Vivek, Locked in place. State-building and late industrialization in India, Oxford, Princeton University Press, 2003.

Evans, Peter, Instituciones y desarrollo en la era de la globalización neoliberal, Bogotá, ILSA, 2007.

Geddes, Barbara, Politician's dilemma, building state capacity in Latin America, Berkeley, University of California Press, 1996. 
Pablo Andrade

López Castellano, Fernando, "Economía política del desarrollo. Análisis poscolonial y 'malos samaritanos' ", Problemas del Desarrollo, vol.43 (169), 2012, pp. 27-50.

Moore, Barrington, Los orígenes sociales de la dictadura y de la democracia: el señor y el campesino en la formación del mundo moderno, Barcelona, Península, 2002.

Pierson, Paul, Politics in time: history, institutions, and social analisis, Oxford, Princeton University Press, 2004.

Smith, Adam, Investigación sobre la naturaleza y causas de la riqueza de las naciones, México, Fondo de Cultura Económica, 2000. 